\title{
The effect of music on pain and vital signs of children before and after endoscopy
}

\author{
Alireza Sabzevari ${ }^{1}$, Hamidreza Kianifar ${ }^{1}$, Seyed Ali Jafari ${ }^{1}$, Masumeh Saeidi ${ }^{2}$, Hamid Ahanchian ${ }^{1}$, Mohammad \\ Ali Kiani ${ }^{1}$, Lida Jarahi ${ }^{1}$
}

${ }^{1}$ Faculty of Medicine, Mashhad University of Medical Sciences, Mashhad, Iran

${ }^{2}$ Student Research Committee, Faculty of Medicine, Mashhad University of Medical Sciences, Mashhad, Iran

\section{Type of article: Original}

\begin{abstract}
Background and Aim: Gentle music has relaxing and pain reducing effects. In this study, the effect of music on patients' vital signs and pain was investigated before and after endoscopy.

Methods: This clinical trial study was conducted on 100 children from seven to fourteen years of age in Gha'em Hospital, Mashhad in 2015. Children were divided into two equal groups (case group=50 and control group=50). The control group received endoscopy according to the standards, without any other procedure. For the case group, a classic musical piece by Clayderman was played during endoscopy (from the time of entering the endoscopy room to the end of the process). After conducting endoscopy, FALCC scale and Baker-Wong pain scale were filled for both groups. In addition, children's vital signs including: heart rate (pulse), diastolic and systolic blood pressure were measured before and after endoscopy for both groups. Data analysis was conducted using SPSS16 with the help of Mann-Whitney and Chi-square tests.

Results: No significant difference was found in age, gender distribution of case or control groups ( $p>0.05)$. Heart rate and diastolic blood pressure was significantly lower in the music (case) group compared to the control group before endoscopy $(\mathrm{p}=0.012)$. In addition, pain score in patients of the music group was lower than the control group $(\mathrm{p}<0.05)$.

Conclusion: Playing music for children during endoscopy can reduce pain and anxiety in patients before and after endoscopy.

Keywords: Music; Endoscopy; Blood Pressure; Pain; Children
\end{abstract}

\section{Introduction}

Throughout history, art has been a tool for adaptation, flexibility, creativity, love, friendship and relaxation. Among the arts, music was very effective due to having force, movement and inherent attraction and it has engaged humans extraordinarily. Since music originates from the nature of humans, every human can understand part of it within their soul and as a language, can transfer or receive concepts. Contrary to old myths that consider the magical power of music, the major focus of today's world is on music due to its special physical and mental effects and its scientifically defined properties that have special advantages in therapeutic methods. Two major properties of music that are applicable in therapy are rhythm and sound. The rhythmic nature of music can be used to facilitate people's rhythm, including the range of movements, the speed of learning, breathing and relaxation and it can provide interaction between patients via harmonizing group behaviors. Various effects of the rhythmic nature of music in heart rate, skin and muscle reactions, and brain waves as well as various effects of music on mood and emotional reactions of the listener are fully identified and proposed (1). Music reduces patients' anxiety by reducing pain and the miraculous effect of it in reducing burning sensation has been confirmed. In addition, it has been effective in reducing pain by affecting the feeling and nerves that transfer pain in cancer patients (2). Research shows that music therapy sessions along with discussions have significantly reduced anxiety in case groups compared to control groups. Music therapy can be used as a non- pharmacological method to improve patients' chronic pain and

\section{Corresponding author:}

Dr. Mohammad Ali Kiani, Department of Pediatrics, Ghaem Hospital, Mashhad University of Medical Sciences, Mashhad, Iran. Tel: +98.5138412069, Fax:+98.5138411067, Email: Kianima@mums.ac.ir

Received: July 12, 2016, Accepted: October 28, 2016, Published: July 2017

iThenticate screening: October 28, 2016, English editing: May 12, 2017, Quality control: June 14, 2017

(C) 2017 The Authors. This is an open access article under the terms of the Creative Commons Attribution-NonCommercialNoDerivs License, which permits use and distribution in any medium, provided the original work is properly cited, the use is non-commercial and no modifications or adaptations are made. 
suffering. However, it should be noted that the type of music is very effective in alleviating pain, since inappropriate music can exacerbate the feeling of pain in patients. As a supportive method, music therapy can reduce anxiety before surgery and discomfort after it. It also reduces pain and anxiety in patients who need critical care (1). In 1985, Goldstein investigated the effect of selective music on the limbic system and autonomic nervous system control center and showed its effect on alleviating behavior (1). Another group of researchers showed the effect of music on movement and muscular reactions. Researchers investigated the effect of music by measuring signs and muscle tape (13). Researchers have shown that music therapy has been one of the successful methods in reducing and alleviating pain and this effect is created mentally by preoccupying the person (paying less attention to pain) as well as affecting hormones, heart rate, blood pressure and electronic changes in muscles (1). In a meta-analysis conducted by Tam et al., data analysis showed that listening to music during colonoscopy significantly reduces the time of conducting this process and reduces the amount of sedative used (3). In another meta-analysis conducted by Rudin et al., results showed that listening to music during endoscopy results in lower levels of anxiety, less need for sedatives and reduction in the total time of process (4). In another study conducted in Iran in 2008 on the effect of music on patients' anxiety during endoscopy and colonoscopy, by measuring blood pressure, it was shown that patients of the case group had lower systolic and diastolic blood pressure with higher arterial oxygen saturation compared to the control group. However, these differences were not significant. In addition, the average time of conducting the process was higher in the control group compared to the case group (5). Endoscopy of the digestive system is a diagnostic and therapeutic method for digestive diseases in children. Due to their being sensitive with low threshold for pain tolerance, some methods should be found to reduce children's pain and anxiety while conducting this process. In this study, it was attempted to investigate the effect of music on vital signs of patients and their anxiety during endoscopy.

\section{Material and Methods}

\subsection{Research design and participants}

This clinical trial was conducted from June-September 2015 in an endoscopy ward of Gha'em Hospital in Mashhad. This study was conducted on 100 children of seven to fourteen years of age who were candidates of esophagogastroduodenoscopy for any reason and whose endoscopy was performed in Gha'em Hospital of Mashhad. Gha'em Hospital is one of the two educational hospitals in Mashhad affiliated to Mashhad University of Medical Sciences. This educational hospital receives patients from Mashhad and other patients referring from the northeast and southeast of Iran. Children were divided into case group $(\mathrm{n}=50)$ and control group $(\mathrm{n}=50)$. They were randomly attributed to case (50 children) and control (50 children) groups.

\subsection{Selection criteria}

\subsubsection{Inclusion Criteria}

Inclusion criteria in this study were children of seven to fourteen years of age and indications for conducting endoscopy including upper bleeding, chemical burning of esophagus etc.

\subsubsection{Exclusion Criteria}

Exclusion criteria were hearing disorder, not wanting to listen to music and being under seven years of age.

\subsection{Intervention}

In the case and control groups, $0.1 \mathrm{mg} / \mathrm{kg}$ midazolam with maximum dose of $3 \mathrm{mg}$ was prescribed for reducing patients' pain. For the case group, classic music by Clayderman was played during endoscopy (from entering the endoscopy room until the end of the process) using a digital $\mathrm{mp} 3$ player and two speakers. After conducting endoscopy, FALCC scale and Baker-Wong pain scale $(7,8)$ were filled by a technician and a nurse for both groups. FALCC scale is a test composed of five factors of face, activity, legs, crying, and consolability, where the observer scores these factors based on available condition between 0 and 20. Baker-Wong pain scale is also a simplified tool to measure the amount of pain in patients where six smiley faces are shown to the patient and they are asked to select one face based on their state. This tool encompasses five drawn images from a smiley face which represents no pain to a teary face that shows unbearable pain, and they are scored between zero and five. In addition, children's vital signs including heart rate, diastolic and systolic blood pressure were measured before and after endoscopy for all children. Finally, a checklist containing demographic and obtained data were filled for each child.

\subsection{Outcomes}

The aim of this study was to investigate the effect of music on pain reduction in children under endoscopy. Another objective of this study was to measure heart rate and systolic and diastolic blood pressure in children of case and control group. 


\subsection{Sample Size}

In a study conducted in the endoscopy ward of Gha'em Hospital of Mashhad, sample size was determined considering the formula of sample size and pain variable in case and control groups to be 50 subjects for case and 50 subjects for control group with confidence level of $90 \%$ and power of $90 \%$. This method of determining sample size was conducted based on similar previous studies (6).

\subsection{Randomizing and Double Blinding}

In this double-blind clinical trial, children were randomly attributed to case and control groups such that children referring on odd days were placed in the case group and those referring on even days were attributed to the control group. FALCC scale and Baker-Wong pain checklists were filled for both groups before and after intervention by a technician and a nurse, who were not aware of the case and control groups. In addition, heart rate and blood pressure were measured by these personnel before and after intervention.

\subsection{Statistical Analysis}

Collected data were analyzed using Mann-Whitney and Chi-square tests using SPSS11.5 software. In all calculations, $\mathrm{p}<0.05$ was considered as significance level.

\subsection{Research Ethics}

This study was the thesis of an M.D. student approved by the Ethics Committee of Mashhad University of Medical Sciences (code 8066). Attending this study was voluntarily and participants were allowed to leave the study without any response whenever they wanted. When conducting this study, sufficient explanations were provided by authors for patients and their parents on the plan and the way of conducting it, and parents' written consent was obtained. Possible advantages and dangers were explained for patients and their parents. Furthermore, the way of compensating possible dangers were explained for them in detail. In addition, patients and their parents' possible questions were answered and one of the researchers' phone number (a pediatrician) was given to all participants of the study and this physician answered all questions of parents and patients. Moreover, when conducting the study, sample size was considered by researchers while respecting them and observing patients' rights as well as obtaining the trust of all participants.

\section{Results}

Of both the case and control groups, 49 subjects (47.1\%) were male and 55 (52.9\%) were female. No significant difference was observed in children under study in the case and control groups $(\mathrm{p}=0.07)$. The mean age of the children was $9.94+2.9$ years and this difference was not significant in both groups $(\mathrm{p}=0.278)$. Mean heart rate, systolic and diastolic blood pressure in case and control group is shown in Table 1 before and after endoscopy. Comparing mean heart rate before and after endoscopy in both groups using Mann-Whitney test, showed that heart rate in the music group was significantly lower before and after endoscopy compared to the control group ( $\mathrm{p}<0.000)$. Results of the Mann-Whitney statistical test showed that no significant difference exists in either group in terms of systolic blood pressure before and after endoscopy $(\mathrm{p}=0.682, \mathrm{p}=0.874)$. Results of the Mann-Whitney statistical test showed that diastolic blood pressure before and after endoscopy, was significantly lower in the music group compared to the control group ( $\mathrm{p}=0.012)$. However, this supposition was not right for diastolic blood pressure after endoscopy $(\mathrm{p}=0.267)$. In addition, the difference of diastolic blood pressure before and after endoscopy showed a significant difference between the two groups $(\mathrm{p}=0.008)$.

Table 1. A comparison of heart rate, systolic and diastolic blood pressure before and after endoscopy for case and control groups

\begin{tabular}{|c|c|c|c|c|c|c|c|c|c|}
\hline \multirow[t]{2}{*}{ Variable } & \multicolumn{2}{|l|}{ Heart rate } & \multirow[t]{2}{*}{$\begin{array}{l}\mathrm{p}- \\
\text { value }\end{array}$} & \multicolumn{2}{|c|}{$\begin{array}{l}\text { Systolic blood } \\
\text { pressure }\end{array}$} & \multirow[t]{2}{*}{$\begin{array}{l}\mathrm{p}- \\
\text { value }\end{array}$} & \multicolumn{2}{|c|}{$\begin{array}{l}\text { Diastolic blood } \\
\text { pressure }\end{array}$} & \multirow[t]{2}{*}{$\begin{array}{l}\mathrm{p}- \\
\text { value }\end{array}$} \\
\hline & $\begin{array}{l}\text { Control } \\
\text { group }\end{array}$ & $\begin{array}{l}\text { Case } \\
\text { group }\end{array}$ & & $\begin{array}{l}\text { Control } \\
\text { group }\end{array}$ & $\begin{array}{l}\text { Case } \\
\text { group }\end{array}$ & & $\begin{array}{l}\text { Control } \\
\text { group }\end{array}$ & $\begin{array}{l}\text { Case } \\
\text { group }\end{array}$ & \\
\hline $\begin{array}{l}\text { Before } \\
\text { endoscopy }\end{array}$ & $98 \pm 1.77$ & $80+1.85$ & 0.000 & $93+1.31$ & $92+1.31$ & 0.87 & $62+1.18$ & $58.5+1.08$ & 0.01 \\
\hline $\begin{array}{l}\text { After } \\
\text { endoscopy }\end{array}$ & $115 \pm 1.95$ & $98+1.41$ & 0.000 & $103+1.54$ & $103+0.93$ & 0.68 & $69+1.19$ & $67+1.11$ & 0.26 \\
\hline $\begin{array}{l}\text { Difference } \\
\text { before and } \\
\text { after }\end{array}$ & $17 \pm 0.68$ & $17.5+1.18$ & 0.81 & $10+0.61$ & $11+0.69$ & 0.31 & $6.5+0.41$ & $9+0.9$ & 0.008 \\
\hline
\end{tabular}




\section{Discussion}

In this clinical trial, endoscopy results of 104 children were compared and evaluated in the form of two groups of case (54 children) and control (50 children) on the effect of music on heart rate, blood pressure and pain in patients. Of these children, 49 subjects $(47.1 \%)$ were male and $55(52.9 \%)$ were female. In terms of age, most children were between 8 and 12 years old (43.3\%), over 12 years old (31.7\%) and under 8 years old (25\%). This sample size seems to be appropriate compared to similar studies. For example, in the study by Smolen, only one 32 -subject sample was investigated for both groups (9). Age and gender were of normal distribution in the study and this complied with most studies conducted in this field (10-12). Vital signs including heart rate, systolic and diastolic blood pressure of patients can act as an index to show patients' anxiety. In our study, a significant difference was observed in heart rate before and after endoscopy in case and control groups $(p<0.001)$; however, this difference was not significant in either of the groups $(\mathrm{p}=0.811)$. In terms of systolic blood pressure, no significant difference was observed before and after endoscopy or the difference between these values in case and control groups ( $\mathrm{P}=0.874$ and $\mathrm{P}=0.682$ and 0.314 ). However, diastolic blood pressure before endoscopy showed a significant difference between two groups ( $\mathrm{p}=0.012)$. In addition, the difference in diastolic blood pressure before and after endoscopy was significantly lower in the case group compared to the control group ( $<<0.001$ ). In a study conducted by Kiani et al. on the effect of music on vital signs, pain and anxiety, heart rate was $20 \mathrm{bpm}$ higher in the control group compared to the case group; however, no significant difference was observed in average arterial pressure in both groups (6). In the study by Raj Kotwal, it was shown that music influenced systolic and diastolic blood pressure and the number of patients' breaths, and there had been a significant difference between case and control groups; while, no significant difference in heart rate was observed in both groups (13). In a similar study conducted by Tazakori et al. in Ardebil, results showed that no significant difference exists between case and control groups in terms of systolic and diastolic blood pressure in various intervals (5). In the present study, FALCC scale and Baker-Wong pain scale were used to evaluate pain in patients before, during and after endoscopy. Results of the Baker-Wong scale showed that the difference in score of this test before and after endoscopy was significantly higher in the case group compared to the control group $(\mathrm{p}<0.000)$. On the other hand, average score of FALCC scale in both groups showed that the score of this test was significantly higher in case group compared to control group $(\mathrm{p}<0.000)$ such that the group that listened to music, suffered from less pain compared to the control group. In the study by Ikonomidou et al, not only was no significant difference observed in vital signs of both groups, but also, they could not prove this difference to score pain or degree of well-being or to reduce doses of taking sedatives and drugs (14). In their study, Harikumar et al. concluded that despite the fact that no difference was observed in pain scores of both groups, discomfort score, time of recovery and doses of midazolam taken, were significantly lower in the case group compared to the control group (15). The study by Kiani et al. (2013) also showed that music can significantly decrease pain and anxiety score in the case group compared to the control group (6). On the other hand, there are studies such as Good (1995), Tanabe (2001), Kwekkeboom (2003), and Richard (2007) that have not been able to prove the effect of music on pain reduction $(4,16-18)$. Although in such studies, patients and medical team's satisfaction has usually been significantly more in the music group compared to the control group. Therefore, instrumental differences including the type of music selected, the number of patients under study and ignoring factors like the environment and personnel of the endoscopy room can justify such difference. Not investigating patients and medical team's satisfaction, not investigating or deleting other intervening factors including the environment or endoscopy personnel were some limitations of the present study. It is suggested to conduct more studies with a bigger sample size and controlling environmental intervention factors in future.

\section{Conclusions}

In sum, findings of this study showed that playing music for children during endoscopy can reduce their pain and anxiety and can stabilize their vital signs as well as encourage more cooperation in the process of endoscopy. The practical importance of these findings is that they can be used by physicians as a method to reduce pain and anxiety. Conducting a complementary study on efficiency of this method on child candidates for endoscopy with a larger sample size and methodology of this study can be a great path for later studies in the future.

\section{Acknowledgments:}

This study is extracted from the thesis by Mohammad Reza Jom'eh Zadeh, M.D. student, Mashhad University of Medical Sciences. All patients and personnel of the endoscopy ward of Gha'em Hospital are appreciated for assisting the author in conducting the present study.

\section{Conflict of Interest:}

There is no conflict of interest to be declared. 


\section{Authors' contributions:}

All authors contributed to this project and article equally. All authors read and approved the final manuscript.

\section{References:}

1) Poslusny SM. Street music or the blues? The lived experience and social environment of depression. Public Health Nurs. 2000; 17(4): 292-9. doi: 10.1046/j.1525-1446.2000.00292.x. PMID: 10943777.

2) Kiani MA, Naghafi M, Jafari SA, Ghayour mobarhan M, Mohammadi Sh, Saeidi M, et al. Effects of Music on Pain, Anxiety and Vital Signs of Children during Colonoscopy. Life Science Journal. 2013; 10(12): 313.

3) Rudin D, Kiss A, Wetz RV, Sottile VM. Music in the endoscopy suite: a meta-analysis of randomized controlled studies. Endoscopy. 2007; 39(6): 507-10. doi: 10.1055/s-2007-966362. PMID: 17554644.

4) Richards $T$, Johnson J, Sparks A, Emerson H. The effect of music therapy on patients' perception and manifestation of pain, anxiety, and patient satisfaction. Medsurg Nurs. 2007; 16(1): 7-14. PMID: 17441624.

5) Harikumar R, Raj M, Paul A, Harish K, Kumar SK, Sandesh K, et al. Listening to music decreases need for sedative medication during colonoscopy: a randomized, controlled trial. Indian J Gastroenterol. 2006; 25(1): 3-5. PMID: 16567885.

6) Tam WW, Wong EL, Twinn SF. Effect of music on procedure time and sedation during colonoscopy: a meta-analysis. World J Gastroenterol. 2008; 14(34): 5336-43. doi: 10.3748/wjg.14.5336. PMID: 18785289, PMCID: PMC2744067.

7) Garra G, Singer AJ, Taira BR, Chohan J, Cardoz H, Chisena E, et al. Validation of the Wong-Baker FACES Pain Rating Scale in pediatric emergency department patients. Acad Emerg Med. 2010; 17(1): 504. doi: 10.1111/j.1553-2712.2009.00620.x. PMID: 20003121.

8) Ahmadi A, Bazargan-Hejazi Sh, Heidari Zadie Z, Euasobhon P, Ketumarn P, Karbasfrushan A, et al. Pain management in trauma: A review study. J Inj Violence Res. 2016; 8(2): 89-98. doi: 10.5249/jivr.v8i2.707. PMID: 27414816, PMCID: PMC4967367.

9) Kotwal MR, Rinchhen CZ, Ringe VV. Stress reduction through listening to Indian classical music during gastroscopy. Diagn Ther Endosc. 1998; 4(4): 191-7. doi: 10.1155/DTE.4.191. PMID: 18493472, PMCID: PMC2362603.

10) Kasper, Dennis L. Harrison's principles of internal medicine. 19th edition. New York: McGraw Hill Education Medical; 2015.

11) Pishnamaz Nishaburi R, Hashemian nejad N. Children endoscopic and endoscopic survey of upper and lower gastrointestinal system in 12 years in 1375 Ghaem Hospital. Pediatric doctoral thesis. Faculty of Medicine, Mashhad University of Medical Sciences. 2006.

12) Walsh S. The pediatric colonoscopy. Gastroentrology nursing. 1995; 18(2): 57-61.

13) Geertzen JH, Van Wilgen CP, Schrier E, Dijkstra PU. Chronic pain in rehabilitation medicine. Disabil Rehabil. 2006; 28(6): 363-7. doi: 10.1080/09638280500287437. PMID: 16492632.

14) Good M. A comparison of the effects of jaw relaxation and music on postoperative pain. Nurs Res. 1995; 44(1): 52-7. doi: 10.1097/00006199-199501000-00010. PMID: 7862546.

15) Triller N, Erzen D, Duh S, Petrinec Primozic M, Kosnik M. Music during bronchoscopic examination: the physiological effects. A randomized trial. Respiration. 2006; 73(1): 95-9. PMID: 16293960, doi: $10.1159 / 000089818$.

16) Tazakori Z, Amani F, Karimollahi M. The Effect of Music Therapy on Patients' Blood Pressure in Endoscopy Unit in Bou-Ali hospital, Ardebil. Iranian Journal of Nursing and Midwifery Research. 2007; 12(1): 10-2.

17) Tanabe P, Thomas R, Paice J, Spiller M, Marcantonio R. The effect of standard care, ibuprofen, and music on pain relief and patient satisfaction in adults with musculoskeletal trauma. J Emerg Nurs. 2001; 27(2): 124-31. doi: 10.1067/men.2001.114386. PMID: 11275859.

18) Kwekkeboom KL. Music versus distraction for procedural pain and anxiety in patients with cancer. Oncol Nurs Forum. 2003; 30(3): 433-40. doi: 10.1188/03.ONF.433-440. PMID: 12719743. 